\title{
ESTUDO DA TÉCNICA DE MINIMIZAÇÃO DE FLUIDO DE CORTE EM PROCESSOS DE USINAGEM
}

Saulo Queiroz Figliuolo1; Daniel Vianna Goes Araujo1; Lucas de Carvalho César; Fernanda Miranda Torres ${ }^{1}$

${ }^{1}$ SENAI CIMATEC - Av. Orlando Gomes, 1845 - Piatã; Salvador - BA; saulo.figliuolo@fieb.org.br

Resumo: O objetivo deste trabalho é realizar um estudo sobre as técnicas de minimização de fluido de corte em processos de usinagem. Diante dos danos ambientais provocados pela utilização de fluidos de corte nos processos de usinagem, estudos vem dando ênfase a tecnologias ambientalmente que visem à preservação do meio ambiente e conformidade com normas ambientais. O setor industrial busca constantemente alternativas que possam substituir ou reduzir o uso de fluidos de corte na usinagem de metais, dentre elas, destaca-se a usinagem sem fluido de corte e a técnica de Mínima Quantidade de Lubrificante (MQL).

Palavras-Chave: usinagem; fluido de corte; lubrificante

\section{STUDY OF THE CUTTING FLUID MINIMIZATION TECHNIQUE IN MACHINING PROCESSES}

Abstract: The aim of this paper is to conduct a study on cutting fluid minimization techniques in machining processes. Given the environmental damage caused by the use of cutting fluids in machining processes, studies have emphasized environmentally friendly technologies aimed at preserving the environment and complying with environmental standards. The industrial sector is constantly looking for alternatives that can replace or reduce the use of cutting fluids in metal machining, among them the machining without cutting fluid and the Minimum Lubricant Quantity (MQL) technique.

Keywords: machining; cutting fluid; lubricant 


\section{INTRODUÇÃO}

Em um período recente, as indústrias tinham como objetivo principal à fabricação de produtos com a estratégia somente de satisfazer aspectos tecnológicos e econômicos. Atualmente, esse objetivo passou a ter como componente adicional os aspectos ambientais de fabricação, a questão ambiental tem fomentado as indústrias, centros de pesquisas e universidades a pesquisarem processos de produção alternativos, criando tecnologias que minimizem a produção de resíduos agressivos ao meio ambiente. Diante das preocupações ambientais provocadas pela utilização de fluidos de corte nos processos de usinagem, forte ênfase é dada a processos que visem à preservação do meio ambiente e conformidade com normas ambientais, como ISO 14000, TRGS, EPA (EUA), Diretivas EC (União Europeia), entre outras [1].

Além dos aspectos ambientais e saúde do trabalhador, os custos para eliminação de fluidos influenciam significativamente no custo total de produção [2]. Visto os impactos ambientais, econômicos e trabalhistas, o setor industrial vem buscando alternativas que possam substituir o uso de fluidos de corte na usinagem de metais. Dentre elas, destaca-se a usinagem sem fluido de corte e a técnica de Mínima Quantidade de Lubrificante (MQL). A técnica MQL consiste na atomização de uma quantidade mínima de fluido na região de corte com o objetivo de lubrificar e reduzir o atrito entre a ferramenta e a peça [3-7].

Por ser um tema de grande relevância, muitas pesquisas estão sendo realizadas nesse âmbito, visando otimizar a utilização dos fluidos de cortes mantendo a produtividade e qualidade das peças. $O$ presente trabalho foi desenvolvido com 0 intuito de realizar uma breve revisão bibliográfica sobre fluidos de corte nos processos de usinagem e quais os impactos associados à sua utilização.

\subsection{FLUIDOS DE CORTE APLICADOS EM PROCESSOS DE USINAGEM}

Os principais objetivos dos fluidos de corte em processos de usinagem são: redução do calor gerado no processo; mitigação do desgaste das peças e consumo de energia; melhora no acabamento final da peça. No ponto de vista da refrigeração, 
o fluido de corte tem como função, eliminar o calor sem admitir que ocorram modificações nas peças, assim como promover a remoção dos cavacos metálicos gerados na usinagem e finalmente proteger máquinas e ferramentas contra a corrosão atmosférica [2]. Para desempenhar bem suas funções, o fluido de corte deve ter as seguintes propriedades: baixa viscosidade; capacidade de envolver a peça para estabelecer um bom contato térmico; alto calor específico; alta condutividade térmica; resistir a pressões e temperaturas elevadas sem vaporizar; boas propriedades antifricção e antissoldantes [3]. A utilização dos fluidos deve focar na mínima quantidade necessária sem que haja interferência na qualidade final da peça. Os custos relacionados a refrigeração representam em média 17\% do custo total da peça, um valor significativo quando comparado aos gastos relacionados às ferramentas (em média $2 \%$ a $4 \%$ ) [2-7].

A medida que a velocidade de corte utilizada no processo aumenta, maior é a necessidade de fluidos com altas taxas de penetração na interface da peça/ferramenta, efeito refrigerante eficaz e maior será a pressão requerida no processo para injeção do fluido na região [5-7].

\subsection{MÍNIMA QUANTIDADE DE FLUIDO DE CORTE (MQL)}

A técnica de MQL tem como princípio o uso do óleo de corte sem resíduos, ou seja, redução do fluxo do fluido de corte que é aplicado a elevadas pressões, assegurando assim a função de lubrificação pela utilização do óleo e a função de refrigeração pelo ar comprimido. O método consiste na pulverização de uma quantidade muito pequena de óleo na aresta de corte, a técnica diminui o atrito entre o cavaco e a face de corte da ferramenta, o que leva a um melhor acabamento superficial e vida útil da ferramenta [4].

O spray pode ser transportado para a área de corte de duas formas: por lubrificação externa, na qual o lubrificante é conduzido através de um local para a superfície de corte ou por refrigeração interna, na qual o lubrificante é transportado diretamente através de furos de lubrificação nas ferramentas integradas [6]. Comparando a técnica de MQL com a utilização de fluidos de corte tradicionais, 
existem desvantagens em relação a custos adicionais visto a necessidade de pressurização do ar. Além disso, o vapor, a névoa e a fumaça de óleo formados podem ser considerados subprodutos indesejáveis, necessitando de um sistema de exaustão [7].

A utilização da técnica MQL é ecologicamente adequada e oferece baixos riscos à saúde dos operadores, mas desde que os aspectos relativos à coleta de resíduos sejam considerados. As máquinas devem possuir vedação adequada e sistemas de aspiração e coleta de cavacos e, principalmente, da névoa de óleo atomizada. As gotículas de óleo suspensas no ar, se não coletadas, se espalham rapidamente, contaminando o ambiente fabril [6].

\subsection{TÉCNICAS ALTERNATIVAS}

Conforme supracitado, técnicas de MQL têm sido largamente adotadas nos processos de fabricação, entretanto, a utilização de óleo (em quantidade mínima) sendo arrastado por uma massa de ar comprimido, seja este disponibilizado com o auxílio de um bocal externo ou passando através da ferramenta de corte, traz consigo algumas desvantagens associadas. Diante dos problemas identificados, alguns estudos têm sido realizados na tentativa de mitigar tais situações e propostas de novos sistemas de lubrificação enxuta para processos de usinagem quase seco têm sido desenvolvidos [8]. Como exemplo, é possível apresentar um novo sistema chamado "sistema de fornecimento direto de gota de óleo" (direct oil drop supply system - DOS). Este é compreendido por um conjunto de peças e equipamentos onde o principal deles é uma bomba de engrenagens que pressuriza o óleo e este, em uma quantidade muito pequena é direcionado para a região de corte e dispensado em formato de pequenas gotas. Para arrefecimento e remoção dos cavacos o sistema utiliza ar comprimido (intercalados entre as gotas de óleo liberadas) [9]. 


\section{METODOLOGIA}

O presente trabalho foi desenvolvido com o intuito de realizar uma breve revisão bibliográfica sobre fluidos de corte nos processos de usinagem e quais os impactos associados à sua utilização. Foram pesquisados artigos científicos que analisaram os efeitos de redução na utilização dos fluidos de cortes nos processos de usinagem através da técnica de mínima quantidade de fluido de corte - MQL.

\section{RESULTADOS E DISCUSSÃO}

Estudo realizado por CATAl et al. [10], apresentou a otimização do processo de usinagem com a técnica MQL, através da confecção de bocais e bicos especiais, o trabalho estudou diferentes formas de aplicação dos fluidos de corte variando os tipos de bicos, diâmetros e formatos internos e externos de saída. O estudo dos bocais resulta na redução ou eliminação do efeito da camada de ar e na redução do volume de fluido utilizado no processo, quando se trata de retificações em altas velocidades, pode haver uma redução nas forças de corte em até $60 \%$ e na rugosidade em $20 \%$ [11]. Com essas adequações propostas ao processo de retificação é possível prever possíveis lucros no setor industrial, uma vez que essas melhorias minimizam o desgaste de ferramentas, forças de corte e consequentemente a quantidade de fluido exigida $[10,12]$.

Estudo realizado por WERDA et al [13] realizou estudo com diferentes métodos de arrefecimento e lubrificação, foram comparados o desgaste da ferramenta, rugosidade da superfície da peça e temperatura. Os resultados concluíram que, a rugosidade da superfície foi melhor na aplicação da névoa de óleo e que o uso da velocidade de corte baixa na presença de água/óleo combinados com névoa permitiu atingir o menor desgaste da ferramenta. As medições de temperatura mostraram que o corte molhado foi capaz de manter a temperatura mais baixa na ferramenta de corte em comparação ao corte a seco. No geral, o estudo acima destaca-se pela aplicação mínima de fluido de corte, ou seja, a redução do fluxo de fluido mantendo a qualidade 
do processo ocasionou o resfriamento adequado durante a operação, permitindo a obtenção de desempenho tecnológico e ambiental satisfatório.

Ensaios de torneamento de uma liga de TiAl realizados por Priarone et al. [14], utilizou-se, a aplicação de baixa quantidade de fluido de corte (ou emulsão ou água) através de nebulização, por meio de ar comprimido, destinado a área de corte. Os resultados provaram que, o uso de névoa de emulsão deu melhores resultados do que os de névoa de água pura, visando a vida útil da ferramenta.

Os resultados da vida útil da ferramenta com a névoa emulsão são melhores do que as de MQL com óleo vegetal, comparável com o sistema de uso convencional. Os índices de rugosidade de superfície permitem classificar a névoa emulsão numa posição intermédia entre a lubrificação molhado padrão e MQL. Resultados a utilização do conjunto de ar comprimido como gás portador gota, permitiu uma melhor penetração do fluido de corte entre cunha e a ferramenta. Do ponto de vista ambiental, quando se pulveriza fluidos de corte, a névoa é dispersa no ambiente circundante, perto da máquina ferramenta, tem-se necessário um sistema de aspiração para respeitar os limites de agentes químicos permitidos no ambiente de trabalho. Além disso, quando se utiliza fluidos de corte pulverizadas, a escolha do óleo é crítica. MQL explora óleos vegetais que são tipicamente não-tóxico, biodegradável, e fabricado a partir de matérias-primas renováveis [8-10].

\section{CONCLUSÃO}

Conceitos relacionados à sustentabilidade são aplicados rotineiramente na indústria com o objetivo de minimizar os impactos ambientais causados pela geração de resíduos sólidos por suas atividades. A utilização da técnica de minimização de fluido de corte MQL é ecologicamente adequada e oferece baixos riscos à saúde dos operadores, mas desde que os aspectos relativos à coleta de resíduos sejam considerados. Portanto, especial atenção deve ser dedicada à coleta dos resíduos gerados pelo processo, para que os benefícios da técnica MQL sejam possibilitados em sua totalidade. A redução da utilização de fluidos de corte permite ganhos de 
preservação do meio ambiente, redução de custos e melhores condições de trabalho no ambiente fabril.

\section{Agradecimentos}

Agradecemos ao SENAI CIMATEC, por nos proporcionar o estudo apresentado como também ao professor Guilherme Oliveira de Sousa por nos orientar durante todo o desenvolvimento do estudo.

\section{REFERÊNCIAS}

${ }^{1}$ KLOCKE, F. A. E. G.; EISENBlÄTTER, G. Dry cutting. Cirp Annals, v. 46, n. 2, p. 519-526, 1997.

${ }^{2} \mathrm{NOVASKI}, \mathrm{O}$; ; DÖRR, J. Usinagem sem refrigeração. Máquinas e Metais, v. 398, p. 18-27, 1999.

${ }^{3}$ MACHADO, A. R.; DINIZ, A. E. Vantagens e desvantagens do uso (ou não) de fluidos de corte. Máquinas e Metais, v. 37, n. 419, p. 134-151, 2000.

${ }^{4}$ BOUBEKRI, Nourredine; SHAIKH, Vasim; FOSTER, Phillip R. A technology enabler for green machining: minimum quantity lubrication (MQL). Journal of Manufacturing Technology Management, v. 21, n. 5, p. 556-566, 2010.

${ }^{5}$ GOINDI, Gyanendra Singh; SARKAR, Prabir. Dry machining: a step towards sustainable machining-challenges and future directions. Journal of cleaner production, v. 165, p. 1557-1571, 2017.

${ }^{6}$ ASTAKHOV, Viktor P. Metal cutting theory foundations of near-dry (MQL) machining. International Journal of Machining and Machinability of Materials, v. 7, n. 1/2, p. 1-16, 2010.

${ }^{7}$ STOLL, Alexander et al. Lean and Environmentally Friendly ManufacturingMinimum Quantity Lubrication (MQL) is a Key Technology for Driving the Paradigm Shift in Machining Operations. SAE Technical Paper, 2008.

${ }^{8}$ DÖRR, J.; SAHM, A. A mínima quantidade de lubrificante avaliada pelos usuários. Máquinas e Metais, v. 418, p. 20-39, 2000.

${ }^{9}$ AOYAMA, T. et al. Development of a new lean lubrication system for near dry machining process. CIRP annals, v. 57, n. 1, p. 125-128, 2008.

${ }^{10}$ CATAI, R. E. et. al. Formas de manutenção e métodos de descarte dos fluidos de corte utilizados na usinagem de metais. Congresso brasileiro de engenharia e ciência dos materiais CBECIMAT, p. 2823-2828, 2002.

${ }^{11} \mathrm{RAMESH}, \mathrm{K}$. et al. Coolant shoe development for high efficiency grinding. Journal of Materials Processing Technology, v. 114, n. 3, p. 240-245, 2001. 
${ }^{12}$ BELLOWS, Guy. Low Stress Grinding. For Quality Production. MACHINABILITY DATA CENTER CINCINNATI OH, 1978.

${ }^{13}$ WERDA, Sana et al. Minimum Quantity Lubrication: Influence of the oil nature on surface integrity. Procedia CIRP, v. 45, p. 287-290, 2016.

${ }^{14}$ PRIARONE, Paolo Claudio et al. Tool wear and surface quality in milling of a gammaTiAl intermetallic. The International Journal of Advanced Manufacturing Technology, v. 61, n. 1-4, p. 25-33, 2012. 